\title{
The A-MPM Decision-Making Model For Film Project Investment
}

Hiroki Koyama, Aoyama Gakuin University, Japan

Narihiko Yoshida, Digital Hollywood University, Japan

Kakuro Amasaka, Aoyama Gakuin University, Japan

\begin{abstract}
This paper looks at the financing of commercial film projects in Japan. A scientific approach is used to quantify the factors that film producers and investors use to make investment decisions regarding film projects - a process that was previously unarticulated. The result of this research is the creation of the A-MPM (Amasakalab's Movie Projects Performance Model), a shared decision-making model for film project investment that aims to promote quality investment decisions and support partnerships between film producers and investors during the subsequent process of filmmaking.
\end{abstract}

Keywords: A-MPM Decision-Making Model For Film Project Investment; Film Producers; Investors; Partnerships; Scientific Approach; Commercial Film Projects; Financing

\section{INTRODUCTION}

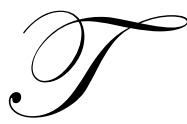

his paper outlines the formulation of Amasakalab's Movie Projects Performance Model (A-MPM), a decision-making model for film project investment that focuses on financing for Japanese commercial film projects. The researchers conducted interviews and surveys of film producers and investors directly involved in financing film projects, defining a set of 45 structural factors that must be considered when making investment decisions. Multivariate statistical analyses were then conducted in order to construct qualitative evaluation standards that film producers and investors use to make film project investment decisions. The A-MPM decision-making model for film project investment was then constructed using these standards, which clarify the rules of thumb that both groups use when making investment decisions.

\section{JAPAN'S FILM INDUSTRY: STATUS AND CHALLENGES}

The size of the film industry in Japan has hovered around 200 billion yen for the past several years. Several factors are thought to be contributing to the lack of market growth, but one major issue is the polarization of box office sales. Compared to films put out by major distribution companies, Japanese films with small and mid-sized budgets (particularly those classified as "independent" films), have suffered from poor box-office performance.

The fall of independent films has contracted the domestic market and played a major role in the homogenization of domestic film releases. This makes the development of independent films a pressing issue in today's film industry. Content funds, one of the primary reasons for investing in independent films, have been used to make many films in recent years, but a good percentage of these have failed in the box office.

In order to pinpoint specific factors contributing to the situation, the researchers interviewed eight film producers and investors currently working in the field. These interviews revealed two key points, which were identified as major factors in the current situation: (1) there is an absence of working partnerships between film producers and investors and (2) no objective evaluation criteria exist for making decisions regarding film project investment. The researchers therefore worked to produce a set of evaluation standards for making film project investment decisions that would resolve these issues and contribute to stronger partnerships between the two groups. 


\section{EVALUATING FILM PROJECTS: PRIOR RESEARCH}

Most prior research seeking to quantitatively evaluate film projects was commissioned by the Agency for Cultural Affairs. The research was carried out by what is now known as Mitsubishi UFJ Research and Consulting Co., Ltd. and published in their Research Report on Content Evaluation and Business Model Surveys. However, the results ultimately could not be used effectively in actual practice. The researchers therefore focused on Research to Establish the A-PPM Patent Valuation Method, prior research involving the valuation of intellectual property.

Amasaka et al. focused on the fact that there was no existing method for valuating patents. And unlike research to assess the monetary value of patents, objective evaluations of the quality of patents themselves (inventions or technologies) have been successful. Amasaka and his colleagues looked at specific problems facing patent valuation from the different perspectives of developers who create patents, intellectual property departments, and patent attorney]. The A-PPM method for patent valuation was established to enable the creation of strategic, quality patents. The method achieved this by having members from the three groups judge the value of a patent by the same standards and strengthening partnerships among them.

\section{CONSTRUCTING THE A-MPM DECISION-MAKING MODEL FOR FILM PROJECT INVESTMENT}

The researchers constructed the A-MPM decision-making model for film project investment based on this prior research. The aim of this model is to support film producers and investors in making investment decisions regarding film projects and to support filmmaking partnerships between the two groups. The A-MPM model consists of two sets of standards: the P-MPM (Producers' Movie Projects Performance Measure) standards to guide film producers in making investment decisions, and the I-MPM (Investors' Movie Projects Performance Measure) standards to guide investors in making investment decisions for film projects. These evaluation standards make it possible to quantify and visualize the way that film producers and investors evaluate film project investments - a process that was previously unspoken and carried out from different perspectives. The structure of the A-MPM model is explained in the next four sections.

\section{Identifying An Investment Decision-making Structure}

In order to identify what standards film producers and investors use to decide whether to invest in film projects, the researchers first interviewed fourteen representatives from these groups (eight film producers and six investors). The interviews revealed the various factors that film producers and investors take into consideration when making investment decisions for film projects (for example, whether the film was in line with current trends or whether it would sell overseas).

The interviews also indicated that both groups either consciously or unconsciously assigned different levels of importance to different evaluation standards. It was also found that the two groups had a shared vocabulary that included terms such as "trendiness", "universality", "profitability", and "hit". Still, even if the terms themselves had a shared meaning, it was clear that the way that the film producers were using them was vastly different from the way that investors were. From these results, it was concluded that film producers and investors: (1) had several different factors on which they based their decisions when evaluating film projects for investment (investment decision factors), (2) that the importance that they attached to those factors resulted in their categorization as well as a specific language to describe them (a structural model for investment decisions), and (3) that investment decisions were actually made using a set of standards (P-MPM and I-MPM) stemming from that structural model.

\section{Listing Investment Decision Factors}

To identify the factors that determine investment, further interviews were conducted with film producers and investors, and actual comments relating to the various factors used to make investment decisions were collected. An affinity diagram was used to sort and categorize the data, resulting in 84 decision-making factors. These 84 factors were discussed with film producers and investors several times in order to streamline them. This process resulted in five groups containing a total of 45 investment decision factors. The groups were: (1) film content, (2) filmmaking plan, (3) advertising plan, (4) distribution plan, and (5) business plan. These factors are listed in Table 1. 


\section{Creating a Model to Determine Investment}

Forty-five factors involved in making investment decisions were examined in terms of importance and relevance. A survey was conducted in order to clarify the different models that producers and investors use to guide their investment decisions.

The topic of the survey was narrowed down to cover only independent animation film projects. The survey consisted of 45 question items, and valid responses were received from 23 people $(15$ film producers and 8 investors). Respondents were asked, "When you are looking to invest in an animation film project, what aspects of the project do you look at most closely?" and asked to rate the importance of each item on a scale of 1 to 10 , with 1 being "completely unimportant" and 10 being "absolutely essential".

Table 1: List of Investment Decision Factors

\begin{tabular}{|c|c|}
\hline \multicolumn{2}{|c|}{ (1) Film content } \\
\hline $1-1$ & Is there are clear theme/message (or target audience)? \\
\hline $1-2$ & Are the opening and closing scenes engaging? \\
\hline $1-3$ & Is there at least once emotionally powerful scene? \\
\hline $1-4$ & Is there something attractive about the main character? \\
\hline $1-5$ & Are the antagonists or obstacles facing the main character effective? \\
\hline $1-6$ & Is the conflict between the characters engaging? \\
\hline $1-7$ & Does it follow the three-act format? (Will it keep audiences interested?) \\
\hline $1-8$ & Is the dialogue engaging? \\
\hline $1-9$ & Are the underlying ideas (originality/unique-ness of the plan) and main idea of the story attractive? \\
\hline $1-10$ & Is the main plotline engaging? \\
\hline $1-11$ & Are the subplots engaging? \\
\hline $1-12$ & Does the conclusion of the film suit the market for when the film is released? \\
\hline $1-13$ & Is there a possibility of gaining popularity with a niche market or local audience? \\
\hline \multicolumn{2}{|c|}{ (2) Filmmaking plan } \\
\hline $2-1$ & Are the characters and casting appropriate? \\
\hline $2-2$ & Do the performers have a high degree of talent/ potential? \\
\hline $2-3$ & Are the screenwriters skilled? \\
\hline $2-4$ & Are the composers skilled? \\
\hline $2-5$ & $\begin{array}{l}\text { Is the filmmaking efficient? (Are the location, artwork, number of photos taken, etc. effective in terms of } \\
\text { time/effort and labor?) }\end{array}$ \\
\hline $2-6$ & Can the producer stay on budget? \\
\hline $2-7$ & Can the producer make a high-quality film? \\
\hline $2-8$ & Can the producer generate a hit movie? \\
\hline $2-9$ & Can the director make a high quality film/product? \\
\hline \multicolumn{2}{|c|}{ (3) Advertising plan } \\
\hline $3-1$ & Can the director's name and/or image generate effective advertising? \\
\hline $3-2$ & Can the performers' names and/or images generate effective advertising? \\
\hline $3-3$ & Can the screenwriters' names and/or images generate effective advertising? \\
\hline $3-4$ & Can the name and/or image of the singer of the theme song generate effective advertising? \\
\hline $3-5$ & Can the name and/or image of the original story generate effective advertising? \\
\hline $3-6$ & Are the promotion and advertising costs appropriate? \\
\hline $3-7$ & Will it be easy to do product or advertising tie-ups? \\
\hline $3-8$ & Will the film be easy to publicize? (Will it be picked up by major media outlets?) \\
\hline $3-9$ & Do the ages of the cast and performers match the target age group? \\
\hline \multicolumn{2}{|c|}{ (4) Distribution plan } \\
\hline $4-1$ & Is the distribution method (chain) appropriate? \\
\hline $4-2$ & Is the timing of the release appropriate? \\
\hline $4-3$ & Can the theme song be sold through tie-ups? \\
\hline $4-4$ & Will it be easy to market? \\
\hline $4-5$ & Will it be easy to put out related books? \\
\hline $4-6$ & Will the film sell overseas? \\
\hline $4-7$ & Are there connections with an foreign distributor with the ability to make the film available overseas? \\
\hline
\end{tabular}




\begin{tabular}{|l|l|}
\hline \multicolumn{2}{|l|}{$(5)$ Business plan } \\
\hline $5-1$ & Is the production team (committee) appropriate for the project? \\
\hline $5-2$ & Are the production fees reasonable? \\
\hline $5-3$ & Is it the maximum budget explicit, and is it certain that the project will not exceed this figure? \\
\hline $5-4$ & Is the production company (financially) reliable? \\
\hline $5-5$ & Will the budget be used appropriately (is there anything inappropriate in the budget?) \\
\hline $5-6$ & Do the members of the production team trust one another? \\
\hline $5-7$ & Does the production team or project pose any legal risks? \\
\hline
\end{tabular}

Data from the surveys was used to construct a model for making investment decisions. Using a cluster analysis, the researchers were able to group the factors guiding the investment decisions of both film producers and investors into seven categories. The seven groups were considered latent factors guiding investment decisions, and the meaning of each group was identified.

The results from the cluster analysis of producer survey data is shown in Figure 1. The first group shown in Figure 1 lists investment decision factors 1-1, 1-2, 1-6, 1-11, 1-12, 1-13,3-9, and 4-2. This group of factors was interpreted as relating to current trends, in terms of characteristics of the consumer market at the time the film would be made.

Group one was therefore labeled as latent factor A1: trendiness. Group two consisted of factors 2-5, 2-7, 2$8,5-1$, and 5-6. The factors in this group were interpreted as relating to the reliability of the film producer, in terms of his or her overall ability to manage the full filmmaking process.

Group two was therefore labeled as latent factor A2: producer reliability. Group three consisted of factors $3-5,4-1$, and 5-2. These factors were interpreted as relating to the profitability of the film in terms of its primary function in the box-office.

The third group was therefore labeled as latent factor A3: profitability. The fourth group included factors 2$9,1-3,1-7,1-9,1-10,2-3$, and 2-4. These factors were interpreted as relating to the universal appeal of the film project - that is, factors that motivate moviegoers regardless of current trends.

Group four was therefore labeled as latent factor A4: Universality.

The fifth group consisted of factors 1-4, 1-5, 1-8, 2-1, 2-2, 4-3, 4-4, and 4-5. This collection of factors was interpreted as relating to the marketability of the film's characters in terms of distribution profitability - the ability to create and sell books and other products related to the film. The fifth latent factor was therefore labeled $A 5$ : character marketability.

Group six was made up of factors 3-1, 3-2, 3-3, 3-4, 3-6, 3-7, 3-8, 4-6, and 4-7. It was interpreted as relating to the ability of the film to make headlines or be publicized. This group was therefore labeled as latent factor A6: publicity potential.

Finally, group seven consisted of factors 2-6, 5-3, 5-4, 5-5, and 5-7. This group of factors was interpreted as relating to security, in term of the legal, financial, and personnel-related risks that the film project was likely face during production. This last latent factor was therefore labeled A7: security.

A structural model for making investment decisions was then set up based on the results of the cluster analysis. Figure 2 shows this model. The entire analysis process was repeated for the data collected from investor surveys, and a second structural model was created. 


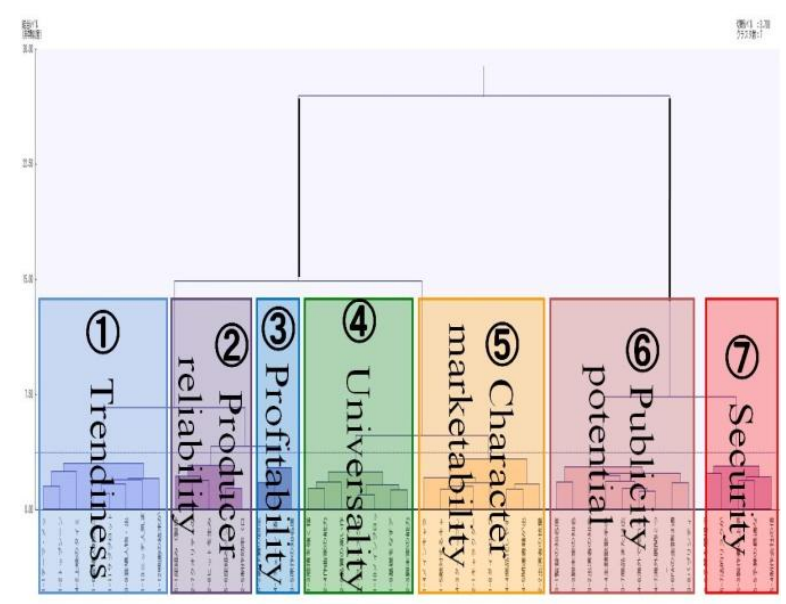

Figure 1: Cluster Analysis Results for Film Producers (Ward's Method)

\section{Creating A-MPM}

The analysis conducted in the section above revealed that film producers and investors evaluate the 45 investment decision factors based on seven different latent concepts. The survey data from each of the two groups was therefore used to investigate the relationship between the 45 investment decision factors and the seven latent factors, as well as between the latent factors and final decisions as to whether to invest in film projects. It was thought that this investigation would yield a set of identifiable evaluation standards.

Based on the structural model for investment decisions created in the prior section, the seven latent factors $\left(\mathrm{A}_{1}-\mathrm{A}_{7}\right)$ were used as primary latent factors, the decision whether to invest in the film project was used as a secondary latent factor $\left(\mathrm{A}_{0}\right)$, and a covariance structure analysis was conducted.

Below are the investment decision-making model formulas generated from the results of the analysis.

(1) Film producer investment decision-making model formulas:

$$
\begin{aligned}
& \mathrm{A}_{0}=0.17 \mathrm{~A}_{1}+0.10 \mathrm{~A}_{2}+0.05 \mathrm{~A}_{3}+0.40 \mathrm{~A}_{4}+0.39 \mathrm{~A}_{5}+0.10 \mathrm{~A}_{6}+0.03 \mathrm{~A} \text { (i) } \\
& \mathrm{A}_{1}=0.19 \mathrm{x}_{1-1}+0.08 \mathrm{x}_{1-2}+0.23 \mathrm{x}_{1-6}+0.28 \mathrm{x}_{1-11}+0.31 \mathrm{x}_{1-12}+0.21 \mathrm{x}_{1-13}+0.15 \mathrm{x}_{3-9}+0.15 \mathrm{x}_{4-2} \text { (ii) } \\
& \mathrm{A}_{2}=0.33 \mathrm{x}_{2-5}+0.48 \mathrm{x}_{2-7}+0.52 \mathrm{x}_{2-8}+0.21 \mathrm{x}_{5-1}+0.18 \mathrm{x}_{5-6} \text { (iii) } \\
& \mathrm{A}_{3}=0.08 \mathrm{x}_{3-5}+0.73 \mathrm{x}_{4-1}+0.32 \mathrm{x}_{5-2} \text { (iv) } \\
& \mathrm{A}_{4}=0.08 \mathrm{x}_{2-9}+0.13 \mathrm{x}_{1-3}+0.16 \mathrm{x}_{1-7}+0.17 \mathrm{x}_{1-9}+0.17 \mathrm{x}_{1-10}+0.15 \mathrm{x}_{2-3}+0.13 \mathrm{x}_{2-4}(\mathrm{v}) \\
& \mathrm{A}_{5}=0.16 \mathrm{x}_{1-4}+0.08 \mathrm{x}_{1-5}+0.14 \mathrm{x}_{1-8}+0.14 \mathrm{x}_{2-1}+0.12 \mathrm{x}_{2-2}+0.12 \mathrm{x}_{4-3}+0.12 \mathrm{x}_{4-4}+0.11 \mathrm{x}_{4-5} \text { (vi) } \\
& \mathrm{A}_{6}=0.30 \mathrm{x}_{3-1}+0.30 \mathrm{x}_{3-2}+0.26 \mathrm{x}_{3-3}+0.24 \mathrm{x}_{3-4}+0.17 \mathrm{x}_{3-6}+0.24 \mathrm{x}_{3-7}+0.33 \mathrm{x}_{3-8}+0.49 \mathrm{x}_{4-6}+0.40 \mathrm{x}_{4-7} \text { (vii) } \\
& \mathrm{A}_{7}=0.98 \mathrm{x}_{2-6}+0.23 \mathrm{x}_{5-3}+0.32 \mathrm{x}_{5-4}+0.28 \mathrm{x}_{5-5}+0.34 \mathrm{x}_{5-7} \text { (viii) }
\end{aligned}
$$




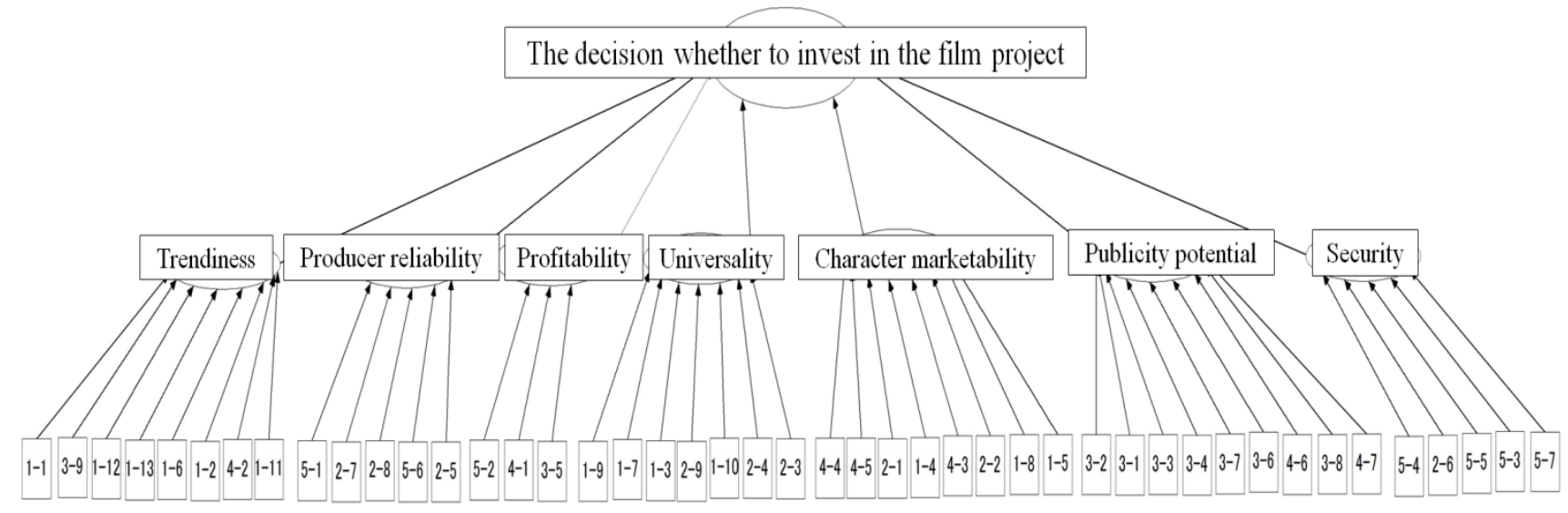

Figure 2: Investment Decision Structural Model for Producers

Formula (i) shows the relationship between the secondary latent factor $\left(\mathrm{A}_{0}\right)$, the film producer's decision to invest in film projects, and the seven primary latent factors that affect investment decisions $\left(A_{1}-A_{7}\right)$.

Formula (ii) shows the relationship between the primary latent factor $\left(\mathrm{A}_{1}\right)$, trendiness, and the eight investment decision factors that comprise it (1-1 ( $\left.\mathrm{x}_{1-1}\right), 1-2\left(\mathrm{x}_{1-2}\right), 1-6\left(\mathrm{x}_{1-6}\right), 1-11\left(\mathrm{x}_{1-11}\right), 1-12\left(\mathrm{x}_{1-12}\right), 1-13\left(\mathrm{x}_{1-13}\right), 3-9$ $\left(\mathrm{x}_{3-9}\right)$, and 4-2 $\left(\mathrm{x}_{4-2}\right)$.

Similarly, formulas (iii) through (viii) show the relationship between each primary latent factor and the investment decision factors that comprise it. The same analysis was conducted on investor survey data, and investment decision-making model formulas were created for both groups.

Using these formulas, P-MPM and I-MPM investment decision-making standards for film projects were created. Figure 3 and 4 shows the P-MPM standards that film producers use to make film project investment decisions. Figure 3 shows evaluations of the latent factors on a 100-point scale, and Figure 4 shows evaluations of investment decision factors on a 10-point scale.

The dashed red lines in both charts show the calculation results obtained when average values from film producer survey data were plugged into the investment decision-making model formulas. The dashed lines in the figure show the standard values that film producers use to make film project investment decisions.

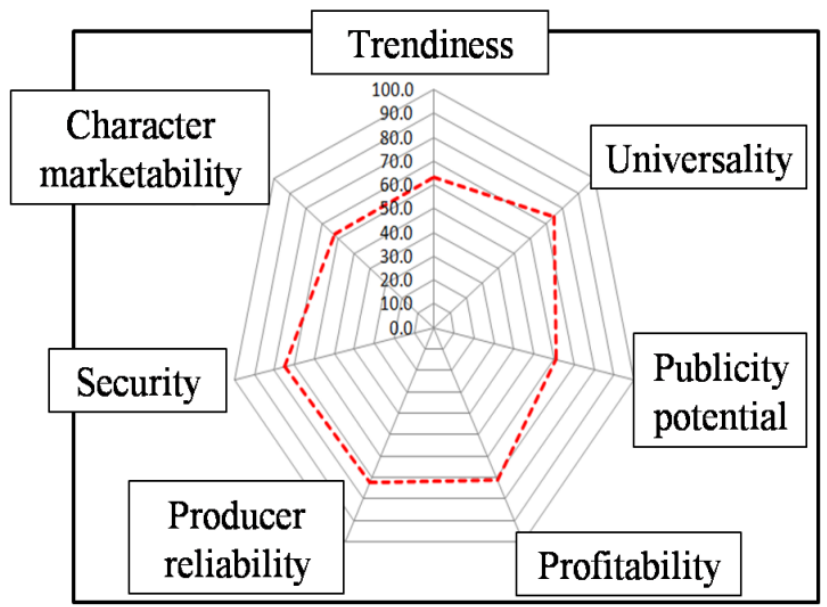

Figure 3: The Evaluations of the Latent Factors on a 100-point Scale 


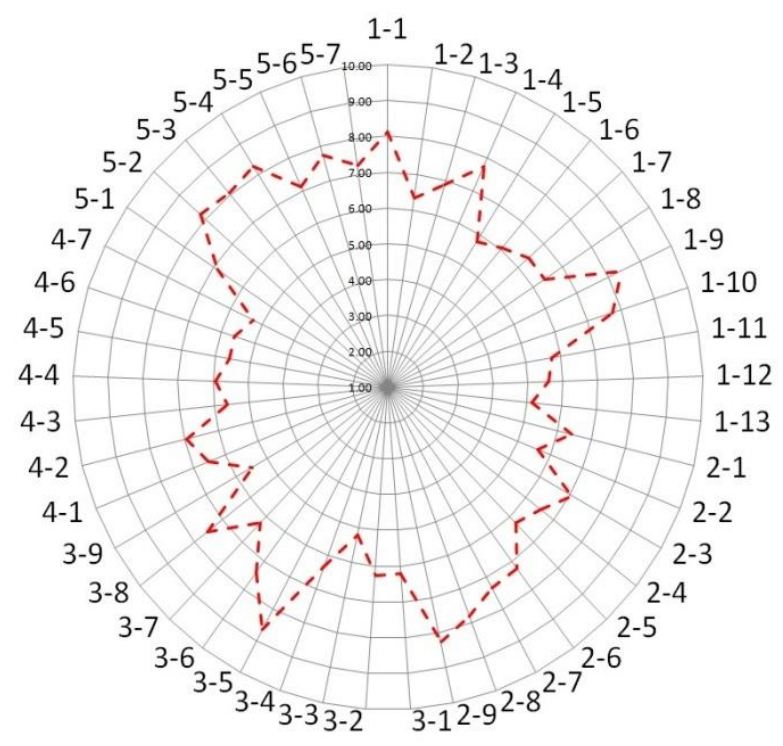

Figure 4: The Evaluations of Investment Decision Factors on a 10-point Scale

A set of standards for investors (I-MPM) was created in the same way. The P-MPM and I-MPM reveal how film producers and investors look at the film projects they are considering and show the projects' strong and weak areas at a glance. The standards also take an unspoken, subjective evaluation process based on rules of thumb and make it objective.

These two sets of standards for making film project investment decisions are what comprise the A-MPM Decision-making Model for Film Project Investment. Using the A-MPM model to aid decision-making allows film producers and investors to form partnerships, exchange feedback, and make the most of their individual talents and abilities when working on film projects together, with an end result of higher-quality filmmaking.

\section{CONCLUSION}

This study focused on the financing of commercial film projects in Japan to construct the A-MPM for film project investment. The researchers are now working to set up on-site surveys to verify the effectiveness of the AMPM model.

The A-MPM uses a scientific approach to enable visualization of the differences between the way film producers and investors evaluate film projects for the purpose of making investment decisions. It also supports stronger partnerships between the two groups and the creation of better films.

\section{AUTHOR INFORMATION}

Hiroki Koyama is a graduate student of the School of Science and Engineering at Aoyama Gakuin University. E-mail: hirokikoyama1215@hotmail.co.jp.

Narihiko Yoshida is a Professor in the School of Digital Communications at Digital Hollywood University, Japan. E-mail: narihiko@hitcontentlab.jp.

Kakuro Amasaka is a Professor in the School of Science and Engineering at Aoyama Gakuin University, Japan. He received his Ph.D. degree in Precision Mechanical and System Engineering, Statistics and Quality Control at Hiroshima University in 1997. His current research and teaching interests are in the general area of production engineering. In particular, he is interested in New JIT. He is a chairman of JOMSA (2008-). E-mail: kakuro_amasaka@ise.aoyama.ac.jp. Corresponding author. 


\section{REFERENCES}

1. Kinema Junpo Film Institute, Movie business data book, Kinema-Junpo, Co., Ltd., 2009.

2. UNIJAPAN, Image contents international and cooperation production infrastructure business report in 2008 fiscal year, UNIJAPAN, 2009.

3. Japan Digital Contents Trust, Inc., Funding scheme of content business, 9-ten, 2004.

4. Agency for Cultural Affairs, Investigation research report concerning contents evaluation in 2004 fiscal year and business model, Investigation society concerning contents evaluation and business model, 2004.

5. M. Tsunoi, K. Anabuki, M. Yamaji and K. Amasaka, A Study of Patent Evaluation Method “A-PPM" for Corporate Strategy, Proceedings of the $5^{\text {th }}$ Japan Society of Kansei Engineering, Takarazuka University of Art and Design, Osaka, Japan, 2009, pp.1-4.

6. K. Amasaka, S. Nitta and T. Kondo, Something with the good patent that the engineer thinks about (the first report and the second report), The Japanese Society for Quality Control, The $52^{\text {nd }}$ Annual Technical Conference, Tokyo, Japan, 1996, pp.17-24.

7. K. Amasaka, 2009, Proposal and Validity of Patent Value Appraisal Model "TJS-PVAM" - Development of "Science TQM" in the Corporate Strategy-, The Academic Journal of China-USA Business Review, Vol.8, No.7, 2009, pp.45-56.

8. K.Anabuki, M.Yamaji and K. Amasaka, Proposal and Validity of Patent Evaluation Method, Proceedings of POM 2008, Gakushuin University, Tokyo, Japan, pp.1276-1287.

9. Kevin.G.R. et al., Leverage strategy of literary property, Diamond Harvard Business Review, 2001.

10. K.Umezawa, Intellectual Property management, Japan Intellectual Property Association, 1999. 